7 meses o más. El fracaso se registraba como la primera fecha en que fallaba el tratamiento con un nucleosídico, un inhibidor de las proteasas o un inhibidor de la transcriptasa inversa no nucleosídico.

El tiempo de tratamiento antes del fracaso se analizó de acuerdo con las curvas de supervivencia de Kaplan-Meier y los factores asociados, según el modelo de riesgos proporcionales de Cox. Estos se estratificaron por centro y se calcularon separadamente para los pacientes con antecedentes (CA) de tratamiento antirretrovírico y sin ellos (SA). En los análisis monofactoriales se incluyeron el sexo, grupo de exposición, raza, infección por hepatitis B o C, diagnóstico de sida, edad, recuento de linfocitos CD4, viremia, y disponibilidad de una prueba de resistencia antes de empezar el TARGA. Las variables del tratamiento fueron el régimen TARGA, la fecha en que comenzó la terapia, y el número de antirretrovíricos que los pacientes recibían como punto de partida. Los recuentos de células CD4 y la viremia se usaron como variables continuas. En pacientes CA, se añadieron como variables el tiempo desde que empezaron a recibir antirretrovíricos, el número acumulado de nucleosídicos tomados, el número de nucleosídicos tomados desde que empezaron el TARGA, y la estrategia del tratamiento previo.

De 9802 pacientes inscritos en el estudio, 3496 llenaron los requisitos de inclusión. La mayoría $(63,8 \%)$ eran CA y, comparados con los pacientes SA, tenían recuentos de CD4 más bajos $(P=$ $0,0066)$, menor viremia $(P<0,0001)$ y habían comenzado la terapia más tempranamente $(P<$ $0,0001)$, con una mediana de 34 meses antes del TARGA y de tres antirretrovíricos. Al inicio del TARGA, 47,5\% de los pacientes recibieron nucleosídicos con los que ya habían sido tratados, 31,2\% comenzaron a tomar uno nuevo y $21,3 \%$, dos nuevos. Durante el seguimiento, 51,9\% de los pacientes en TARGA fueron expuestos a tres clases de antirretrovíricos. En total, 12,7\% experimentaron fracaso a las tres clases de medicamentos; de estos, 16,6\% eran CA y $5,9 \%$, SE.

Para 2003, el tratamiento triple había fracasado en uno de cada 20 pacientes SA y uno de cada seis CA. La incidencia del fracaso fue mucho menor entre los pacientes SA pero aumentó con el tiempo después de empezar el TARGA. La incidencia del fracaso entre pacientes CA se estabilizó después de una baja incidencia inicial los primeros dos años. Se estima que seis años después de iniciar el TARGA, en $20 \%$ de los pacientes CA y $10 \%$ de los SA, el tratamiento triple había fallado. Varios estudios muestran que los pacientes CA tienen una respuesta virológica menos satisfactoria al TARGA que los SA pero, en general, no se observó ninguna diferencia en el riesgo de empeoramiento. Sin embargo, pue- den pasar años desde el fracaso hasta el avance de la enfermedad y quizá se necesite un seguimiento más largo para detectar alguna diferencia. Hasta el momento, la resistencia cruzada a las distintas clases de antirretrovíricos ha sido irreversible, de manera que puede esperarse un aumento en la prevalencia de pacientes con fracaso virológico. Desde el punto de vista individual, esto significa un mal pronóstico y la posible transmisión de virus resistentes a otras personas. En cuanto a las clínicas, es de esperar que los costos aumenten debido al empleo de pruebas diagnósticas más intensivas, medicamentos más caros y un mayor número de medicamentos en cada régimen.

Durante el estudio aumentó notablemente la incidencia de casos nuevos de sida y de muertes, y se observó un número cada vez mayor de fracasos con distintas clases de medicamentos. Sin embargo, no se midió el papel que desempeña el cumplimiento con el tratamiento en el fracaso virológico. Posiblemente el fracaso de algunos pacientes se debió a incumplimiento con el régimen terapéutico. En el futuro, es necesario enfocar la diferencia entre esos pacientes y los que fracasan debido a la resistencia del virus. Se necesitarán nuevas opciones de tratamiento, quizás megaTARGAs o interrupciones del tratamiento. Recientemente se han introducido inhibidores de fusión, con los cuales se suprimió el virus en $20 \%$ de los pacientes a las 48 semanas. Se siguen investigando esta y otras posibilidades.

Según calcula la Organización Mundial de la Salud, para fines de 2005 habrá que tratar a unos tres millones de personas con infección por VIH en países en desarrollo. Es probable que el fracaso sea similar al que se encontró en el estudio descrito y, lamentablemente, que el número de pacientes en quienes fracasa el TARGA siga aumentando en los años venideros. (Mocroft $A$, et al. Time to virological failure of 3 classes of antiretrovirals after initiation of highly active antiretroviral therapy: results from the EuroSIDA Study Group. J Infect Dis. 2004; 190(11):1947-1956.)

\section{Encuesta de salud de escolares del Caribe: urge reforzar los factores protectores}

De 1997 a 1998 participaron en una encuesta de salud en torno a comportamientos riesgosos 15695 adolescentes de nueve países de la Comunidad del Caribe (Antigua, Bahamas, Barbados, Dominica, Guyana, Islas Vírgenes Británicas, Jamaica y Santa Lucía). Este estudio llenó un enorme vacío en la información existente y proporcionó los primeros datos de perspectiva multinacional sobre jóvenes escolares de 10 a 18 años de edad en relación con el comportamiento violento, el sexo, el taba- 
quismo y el consumo de alcohol. Esos hábitos suelen iniciarse a temprana edad; casi la mitad de los varones y una cuarta parte de las niñas ya habían tenido relaciones sexuales; una de cada cinco niñas y dos de cada cinco niños habían participado en actos violentos. Uno de cada seis informó que esas conductas se habían establecido antes de los 13 años de edad.

En los últimos años se ha difundido la idea de que para ayudar a los adolescentes a rechazar esos embates ambientales, no solo es necesario reducir los riesgos que los acosan sino a la vez fortalecer los factores que les sirven de protección. En inglés se habla de esos factores como assets, es decir ventajas, valores o bienes con los que cuenta el adolescente. Por otra parte, se puede fomentar en el joven algo que se ha dado en llamar resilience, que equivale a fortaleza interna, poder de recuperación o capacidad para adaptarse. A continuación se resume un artículo en el que dos investigadores, teniendo en cuenta lo anterior, analizaron los datos de la encuesta de 1997 con el fin de calcular los resultados que podrían esperarse según los factores de riesgo y la presencia o ausencia de factores protectores. La muestra encuestada se consideró representativa de las poblaciones participantes, ya que se seleccionaron aleatoriamente de nóminas escolares oficiales. El número que rehusó participar fue muy bajo y las encuestas fueron confidenciales, con el consentimiento de los padres. Se utilizó un cuestionario de 87 preguntas de selección múltiple que exploraban el desempeño escolar, el ambiente escolar, el uso de alcohol y otras drogas, la salud reproductiva y sexual, el abuso físico y sexual, la honradez, la salud mental y el suicidio, la religiosidad, características familiares, las relaciones con otros, la violencia, la salud en general y la nutrición.

En el análisis se incluyeron cuatro variables dependientes: la violencia, las relaciones sexuales, el consumo de tabaco y el consumo de alcohol. La violencia se definió como haber llevado un arma a la escuela dentro de los 30 días anteriores, haber llevado armas en otras circunstancias, haber pertenecido a una pandilla, y haber sido acuchillado o baleado. Las informaciones sobre sexualidad y uso del tabaco y alcohol se trataron como preguntas dicótomas de respuesta afirmativa o negativa. Las variables sobre factores de riesgo y protectores incluían sus relaciones con otros miembros de la familia, conexión con la familia y la escuela, asistencia a servicios religiosos y religiosidad. Las variables de riesgo comprendieron el abuso sexual y físico, la salud mental y el consumo de drogas por los padres, así como sentir ataques de furia. Los análisis se realizaron por separado para niños y niñas y para tres grupos de edades: 12 años o menos, 13-15 años y 16-18 años. Se empleó la regresión logística para calcular la probabilidad de cada uno de cuatro resultados, según la presencia o no de factores de riesgo y de protección: por ejemplo, se calculó la probabilidad con los factores de riesgo constantes y $0,1,2,3$ ó 4 factores protectores y luego al revés, añadiendo factores de riesgo a factores protectores constantes.

Los análisis de regresión logística estratificados separadamente por sexo y edad fueron consecuentes en los resultados. La asociación más fuerte fue el vínculo entre los sentimientos de furia y cada variable dependiente, tanto en varones y niñas como en todos los grupos de edad. Le siguieron en orden descendiente el absentismo escolar y los antecedentes de abuso. La conexión con la escuela fue el factor protector más fuerte, seguido de la conexión con la familia y la asistencia a servicios religiosos o la religiosidad.

En cuanto al comportamiento violento, se comenzó manteniendo los factores protectores constantes según el promedio conocido en la población. Cuando ninguno de los tres factores de riesgo principales (abuso, absentismo escolar y furia) estaba presente, $21,9 \%$ de los varones y $8,4 \%$ de las niñas participaron en actos violentos. Según se añadían factores de riesgo al modelo, aumentaba la conducta violenta. Con la presencia de los tres factores, la participación en actos violentos alcanzó $91,4 \%$ en los niños y 76,7\% en las niñas. Los aumentos fueron igualmente notables según aumentaba la edad. El análisis con los factores de riesgo constantes y sin factores protectores mostró que $68,1 \%$ de los varones y $75,9 \%$ de las niñas habían participado en actos violentos. El porcentaje disminuyó según se añadían factores protectores; la conexión con la escuela fue el factor de protección más poderoso, que redujo las cifras a $39,9 \%$ y $11,6 \%$, respectivamente. Con los tres factores de protección añadidos al modelo, la participación en actos violentos se redujo a $26,7 \%$ en los varones y a $5,8 \%$ en las niñas. El efecto protector fue notablemente más intenso en las niñas.

Los análisis sobre relaciones sexuales se realizaron del mismo modo descrito para la conducta violenta. Sin ninguno de los factores de riesgo presentes, 35,8\% de los varones informaron de que habían tenido relaciones sexuales, frente a 13,8\% de las niñas. Los porcentajes aumentaron con cada factor de riesgo añadido. Con los tres factores principales de riesgo presentes, disminuyó mucho la diferencia entre los sexos. La conexión con la escuela fue de nuevo el elemento más fuertemente asociado con no haber tenido relaciones sexuales. Por el contrario, la asistencia a servicios religiosos tuvo el vínculo más débil con la abstinencia sexual. Al igual que en el caso de la violencia, hay una menor reducción del riesgo de inicio sexual en los varones 
que en las niñas cuando están presentes los tres factores protectores (el cambio ascendió a 35,1\% y $74,5 \%$, respectivamente).

Siguiendo el mismo modelo, se analizó el hábito de fumar cigarrillos. Los tres factores de riesgo principales en este caso fueron el abuso (y la violencia de los padres en el grupo de 13-15 años de edad), el absentismo escolar y la furia. Con tres factores protectores activos, solo 7,6\% de los varones y $4,8 \%$ de las niñas fumaban. Calculado según los grupos de edad, el hábito osciló entre $2,3 \%$ en los más pequeños y $8,7 \%$ en los de mayor edad. El porcentaje aumentó con cada riesgo añadido al modelo y, con los tres factores presentes, llegó a 49,6\% en los varones y a 37,0\% en las niñas. Manteniendo los riesgos constantes, sin elementos protectores, $51,3 \%$ de los niños y $66,6 \%$ de las niñas fumaban. De nuevo, se añadieron los factores protectores y el más influyente fue la conexión con la escuela, que redujo los porcentajes de fumadores a 9,1\% y 9,8\%, respectivamente.

Los factores de riesgo de tomar bebidas alcohólicas fueron muy similares a los del tabaquismo, pero el consumo de drogas por los padres fue el factor de mayor riesgo para las niñas. El abuso aumentó un poco el riesgo, pero es la furia la que causó mayor elevación de los porcentajes: de 5,8\% a $43,9 \%$ en los varones y de $3,0 \%$ a $53,9 \%$ en las niñas. Sin ningún factor protector en operación y los factores de riesgo constantes, $62,1 \%$ de los varones y $78,7 \%$ de las niñas tomaban alcohol por lo menos una vez a la semana. Al igual que con el hábito de fumar, la conexión con la escuela fue el factor de reducción aislado más poderoso (a 8,6\% en los varones y $2,1 \%$ en las niñas). Con la presencia de los tres factores protectores, hubo una reducción a 3,2\% en los varones y a $0,8 \%$ en las niñas.

En conexión con los cuatro comportamientos analizados se destacan ciertos factores, tanto de riesgo como de protección. Los adolescentes que habían sufrido abuso, los que faltaban a clases y los que indicaron que casi siempre estaban pensando en lastimar o matar a alguien fueron más propensos a informar de que participaban en las cuatro conductas negativas: actos de violencia, relaciones sexuales, consumo de cigarrillos y consumo de alcohol. Otros factores de riesgo recurrentes coincidieron con la violencia y el consumo de drogas por parte de los padres. El abuso fue un factor de riesgo persistente y, en un estudio llevado a cabo en los Estados Unidos, se asoció fuertemente con intentos de suicidio. Asimismo, los datos estadounidenses obtenidos del Estudio Nacional Longitudinal de Salud de los Adolescentes muestran una fuerte asociación entre el abuso físico y sexual que han sufrido y el hábito de fumar, la violencia y la angustia emocional.

Muchas fuentes dan a entender que la gente joven desconectada de la escuela está en riesgo de una serie de conductas deletéreas para su salud. La furia, por otra parte, rara vez se ha estudiado como factor de riesgo. Por lo general, los estudios sobre la violencia suelen considerar al adolescente como víctima o actor, pero la furia abre otra dimensión: la inclinación a cometer un acto violento. Sería de esperar que también tuviera importancia entre los problemas de los adolescentes en otros lugares fuera del Caribe.

El análisis descrito no presenta muchas sorpresas, pues los factores de riesgo y de protección ya se conocen. Sin embargo, muestra claramente que para los jóvenes del Caribe, el riesgo fue acumulativo, como lo fue también la protección. Es de especial interés que cuando los factores de riesgo se mantuvieron constantes, la adición de los factores protectores tuvo el efecto, sorprendentemente fuerte, de disminuir los comportamientos nocivos. Además, la reducción de riesgos y el aumento de la protección funcionaron de manera diferente en varones y niñas. En los varones, la conducta negativa pareció disminuir más con la reducción de riesgos; en las niñas, la disminución fue más intensa cuando todos los factores protectores entraron en el modelo. También quedó claro que las niñas eran más susceptibles que los niños tanto a la presencia de riesgos como a la de factores de protección. La influencia de la escuela fue crucial. Este estudio hace pensar que, además de enfocar la atención en la reducción de los riesgos, es preciso prestar mucha más atención a fortalecer los factores de protección. (Blue RW y Ireland M. Reducing risk, increasing protective factors: findings from the Caribbean Youth Health Survey. J Adolesc Health. 2004;35:493-500.) 